\title{
Armenia: IOI Participation and National Olympiads in Informatics
}

\author{
Vahram DUMANYAN, Armen ANDREASYAN \\ Department of Informatics and Applied Mathematics, Yerevan State University \\ 1 Alex Manoogian, Yerevan, 0025, Armenia \\ e-mail:duman@ysu.am,andreas@ysu.am
}

\begin{abstract}
The article describes technology used to teach programming and preparing for Olympiads in Informatics in Armenia. It describes the current model of organizing the competition: steps, target groups, methodologies of development, evaluation, and the preparation of participants for the different stages of the competition.

Keywords: IOI, olympiad in informatics, teaching programming.
\end{abstract}

\section{IOI Participation}

Armenia started participating in the IOI in 1996 in Hungary. Next year Armenian delegation could not go to the South Africa. Our students won first medal (bronze) in 2002. Since then they returned from an IOI with at least one medal. For us especially significant are IOI'2005 when Vahe Musoyan won gold medal, and IOI'2014 when all four students won medals ( 2 silver and 2 bronze). Since now Armenia has 1 gold , 4 silver and 20 bronze medals. You can find all details in the Statistics page (International Olympiad in Informatics - Statistics).

Medalists of an international olympiads may enter appropriate departments of universities of the country without exams and study for free.

In the first years, team leaders found sponsors for the trip expenses. For the last 15 years, these costs are covered by the Ministry of Education.

Armenian students participate in International Zhautykov Olympiad (Iglikov et. al., 2013) -3 silver and 7 bronze medals, and APIO - 3 bronze medals.

\section{National Olympiad Procedure}

The National Olympiads among school student are held by the Ministry of Education and Science. Every year the schedule of Olympiads is made. The assignments and the 
results of all the school Olympiads held in Armenia are placed in (School Olympiads) and in (Armenian Educational Portal) websites.

YSU Faculty of Informatics and Applied Mathematics is responsible for the National Olympiad of Informatics.

National Olympiad is held in three stages. There are no divisions according to the grade and age. The majority of the participants are students of grades 10-12, but there are also lower grade students. The first phase is the school stage and is held at schools in February. Until 2014-2015 school year, the schools conducted that stage independently and chose their best students. Schoolteachers made the assignments themselves and held the competitions. Sometimes the content and form of their assignments did not correspond to the assignments of next rounds. There are no statistics on the number of participants of those years.

The second stage is regional and is held in early March. Armenia is divided into 10 provinces. On this stage, the capital Yerevan is considered as a separate entity. The students of the provinces gather on the same day and the same time. They solve the problems compiles by the Commission. Before 2014-2015 school year, the juries of every province checked the results according to the provided tests and chose the best students themselves. The biggest turnout was in Yerevan. Yerevan municipality and regional administrations reward the winners of their regions with diplomas. Each province and the capital have their quotas for the participation on the next stage. Yerevan has 20-25 seats and each of the provinces has 4-6 seats. However, some regions sent fewer students or did not send at all.

The third stage is the National. It is held in late March or early April in the computer center of YSU. In the last 10 years, the competition is held for 2 days. As a result, best students get rewards from the Ministry (diplomas, certificates). The Committee decides the number of diplomas. The students that got diplomas, form the selection group.

\section{New Format of Providing National Olympiads}

In 2014, one of the participants of IOI'2013 made new contest management system. It is qualitatively higher than the previous system. The new system makes it possible to hold online contests, to put interactive problems and IOI - format (with subtasks) problems. It was decided to hold the competition of all three stages of the Olympiad with this system, and to hold the first two stages online. Any student mastering programming languages $\mathrm{C}$, $\mathrm{C}++$, Pascal can take part in the first stage, informing the school administration beforehand. The list of the participants is published in the olymp.am according to the school information.

The second stage of Olympiad is held in certain places given by the regional administrations (in Yerevan the Municipality decides the place). The students with best results from the first stage take part in the second stage. According to the decision of the Organizing Committee, the school of the student is not taken into consideration.

The organizing committee also determines the list of participants of the third stage, based on the results of the second one. The quotas of the provinces have been eliminated. As a result, the number of students from Yerevan has been significantly increased. 


\section{Selection Competitions and the Preparation for the IOI}

The selection group is formed according to the results of the national stage of Olympiad. Theoretical and practical classes are held for the group. Then, according to three competitions, four students who will represent Armenia in IOI are determined. For the preparation for the IOI 1-2 week summer camp is held. Last years, not only the members of IOI group take part in Summer Camp, but also the students of selection group, that still study at school. Not only the group leaders held the lessons but also previous years' IOI medalists and participants. The Summer Camp is held at Camp "Ughetsir" of Quantum College, located in the mountain resort of Aghavnadzor, as well as in the YSU Rest House, Tsakhkadzor.

\section{The Role of Online Competitions and the Online Judges}

Under current conditions, it is impossible to succeed without systematic long-term studies. We think that online competitions held for the students are very useful.

Armenian National Olympiad problems can be solved in am.spoj.com. We are grateful to Spoj team for this opportunity. During our training, we use other archives too. Initially, we use Michael Dolinski's website (DOLINSKY, 2013). We would like to single out St. Petersburg cycle of online Olympiads (Olympiads in Informatics: St. Petersburg, Russia), USACO online contests (USA Computing Olympiad), Croatia online contests (Croatian Open Competition in Informatics). Thanks to the organizers for giving the Armenian translations of the competition assignments in their websites. Codeforces' competitions (Codeforces) are useful, too. It also contains numerous resources (descriptions of algorithms, virtual competitions), which are suitable for trainings.

\section{Specifics of National Olympiads}

Programming is a small part of School program of informatics. It is included in $11^{\text {th }}$ grade program, and it has quite superficial presentation. Informatics is not among the examination subjects. Applicants for admission to university programming departments have to pass mathematics and physics or English. Only a few schools have Olympic circles of informatics.

In Armenia everything is concentrated in Yerevan: economy, science, culture, education. One can say that Yerevan dominates the provinces. The population of the provinces is almost twice more than in Yerevan.

For last two years, it has become possible to get information about participation in first two stages due to the online competition of regional stage. We have the following statistics: Fig. 1, Fig. 2, Fig. 3.

The number of the participants from provinces has decreased especially in 3rd stage. 


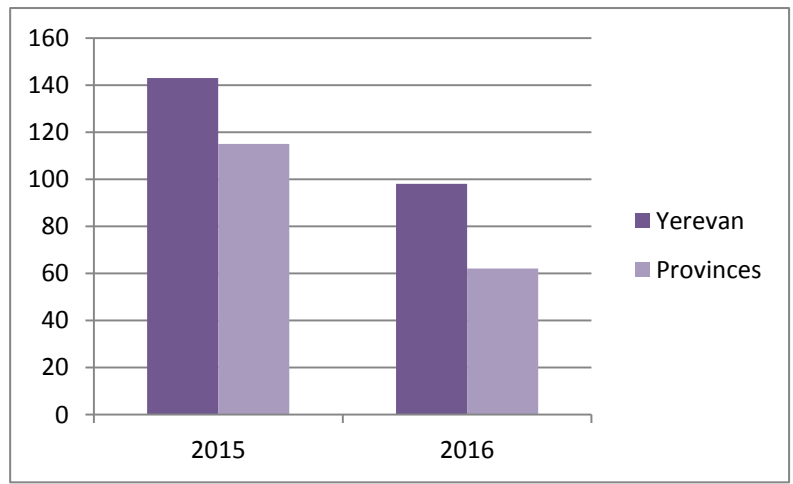

Fig. 1. Number of participants at the 1st stage.

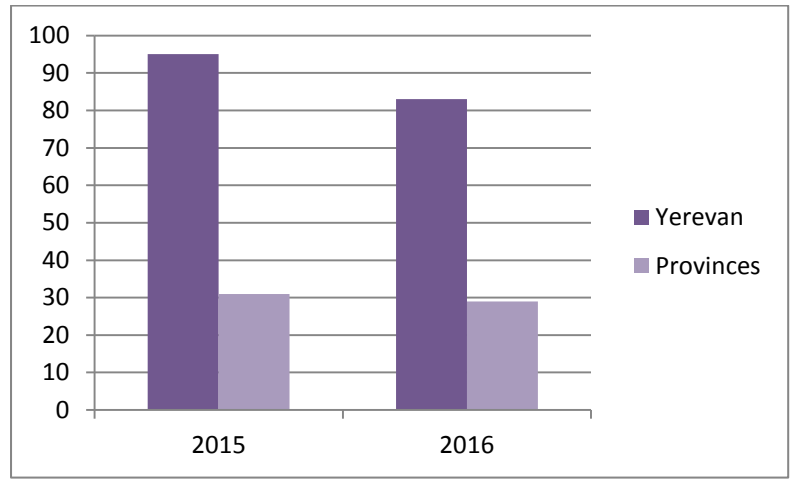

Fig. 2. Number of participants at the 2nd stage.

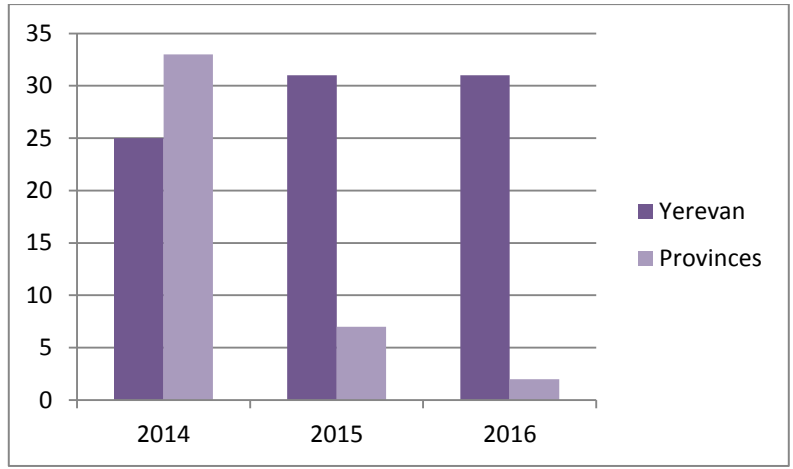

Fig. 3. Number of participants at the 3rd stage.

In the capital city there is majority of two schools. In the following chart you can see representations of schools in the republic stage of National Olympiads in 2016: Fig. 4. 


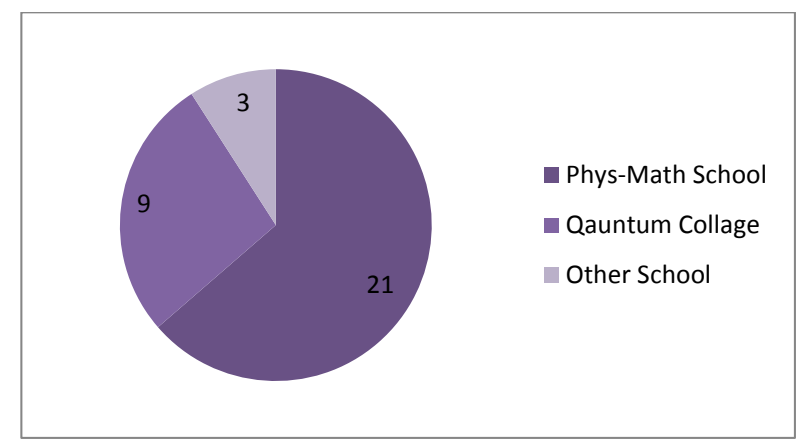

Fig. 4. Participants of 3rd stage of National Olympiads in 2016.

Physics and Mathematics Specialized School is founded in 1965 by academic Artashes Shahinyan. Every year students of the school represent Armenia in the international Olympiads on Informatics, Mathematics, Physics, Chemistry, Biology, Astronomy. In 2015 students of the Phys-Math school got 14 medals from these International Olympiads. Quantum Collage is the first private school and founded in 1991. This school also has good Olympic history and traditions. Until 2014, only 12 participants from each of these two schools were allowed to take part in the second Stage of Olympiads. Now this restriction is removed. The students representing Armenia in the IOI are mostly from those schools. 13 of Armenian 25 medals are of Quantum College and 8 of Physic-Mathematical School. 24 students from 52 participants from 2003 to 2015 were of Quantum College, and 20 students of Physic-Mathematical School. This is explained by the fact that both schools have Olympic groups that work throughout the school year.

However, we are sure that there are talented students in provinces, too, as there are exclusive precedents. School student from the second city of Armenia, Gyumri, won the first medal. In 2012, a student from the southern mountainous part of Armenia, Syunik, was involved in the group and won bronze medal in IOI. He gained his basic knowledge himself through the Internet.

Now we think to take measures to increase the interest and the participation of province students, organize in these two strong schools some kind of distance lessons, online materials accessible for all students in the country. Also we consider switch to the two level contests opening second division for students up to 9-th grade like in Lithuania (Dagienè, Skupienè, 2007), Serbia (Ilić, 2012).

\section{Conclusion}

Armenia has been participating in IOI since 1995 and has achievements. In recent years, great work for the improvement of the quality of National Olympiads has been done. There are some problems with the promotion of the Olympiads. Measures should be taken to spread the necessary knowledge of Informatics and to involve more students and schools in the National Olympiads. 


\section{References}

Armenian Educational Portal. http: //armedu.am

Codeforces. http: //codeforces.com

Croatian Open Competition in Informatics. http://hsin.hr/coci

Dagienė, V., Skupienè, J. (2007). Contests in programming: quarter century of Lithuanian experience. Olympiad in Informatics, 1, 37-49.

Dolinsky, M. (2013). An approach to teaching introductory-level computer programming. Olympiads in Informatics, 7, 14-22.

Iglikov, A., Gamezardashvili, Z., Matkarimov, B. (2013). International Olympiads in Informatics in Kazakhstan. Olympiads in Informatics, 7, 153-162.

Ilić, A., Ilić, A. (2012). IOI trainings and Serbian competitions in informatics. Olympiad in Informatics, 6 , $158-169$

International Olympiad in Informatics - Statistics. http://stats . ioinformatics . org

Olympiads in Informatics: St. Petersburg, Russia.

http://neerc.ifmo.ru/school/io/index.html

School Olympiads (in Armenian). http://olymp.am

USA Computing Olympiad. http://usaco.org

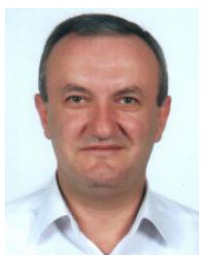

V. Dumanyan, Doctor of Sciences (Mathematics), Yerevan State University; Dean of the Faculty of Informatics and Applied Mathematics.

Organizer of National Olympiads in Informatics (since 2013).

Leader of national team on International Olympiad in Informatics (2007, 2010, 2013-2015).

Director of Armenia Subregion in the ACM ICPC Olympiads (since 2004).

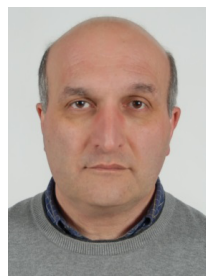

A. Andreasyan, MSc in computer science from Moscow State University. Assistant professor at the Department of Programming and Information Technologies of Faculty of Informatics and Applied Mathematics of the Yerevan State University.

Organizer of the summer camps for preparing the Olympic teams. Organizer of National Olympiads in Informatics. Leader of national team on International Olympiad in Informatics (since 2003). Coach of Yerevan State University teams in the ACM ICPC (since 2003). 